\title{
Analysis of UV-LED curing technology and existing problems of varnish for printed matter
}

\author{
Xiaoli $\mathrm{Li}^{1, \text { a }}$, Shiyong $\mathrm{Luo}^{1}$, Wencai $\mathrm{Xu}^{1}$, Kelin $\mathrm{Mao}^{2}$, Jiangwei Huang ${ }^{2}$, Yong $\mathrm{Xiao}^{2}, \mathrm{Di} \mathrm{He}^{2}$ and Ruiqiang \\ Meng $^{2}$ \\ ${ }^{1}$ Institute of anti-counterfeiting materials \& technology, Beijing Institute of Graphic Communication, Beijing, 102600, \\ China \\ ${ }^{2}$ Guangxi Zhenlong Color Printing and Packing Co. Ltd, Fuchuan Guangxi, 542700, China
}

\begin{abstract}
UV-LED curing $v$ arnish is m ore en vironmental. In or der to $l$ et people under stand UV-LED $\mathrm{c}$ uring $\mathrm{v}$ arnish a nd exi sting $\mathrm{p}$ roblems of U V-LED curing t echnology a nd p rovide reference and theoretical basis for the future development of UV-LED curing varnish, the paper sketched basic composition of UV-LED varnish and curing process and pointed low initiation efficiency a nd $\mathrm{s}$ low $\mathrm{c}$ uring s peed $\mathrm{w}$ ere $\mathrm{t}$ he main $\mathrm{p}$ roblems of $\mathrm{t}$ he $\mathrm{U} \mathrm{V}$-LED 1 ight $\mathrm{c}$ uring technology through referring to a large nu mber of doc uments and related da ta. The solutions are suggested: First, the photoinitiators with absorption spectra matched to emission spectra of LED should be selected; second, monomers with more functional groups should be used.
\end{abstract}

Keywords: UV-LED varnish; photoinitiator; curing speed.

\section{Introduction}

With the improvement of living standards, people are increasingly s eeking high quality packaging. Glazing oil is also known as varnish or glazing paint. It is a colorless, transparent or translucent ink [1]. Coated varnish in the print surface will improve the gloss, water resistance and wear resistance of print. It is able to protect the print, make the print more gorgeous and also convenient for subsequent processing of print [2]. According to the different curing technology, currently varnish on the market can b e d ivided into o ily v arnish ( solvent $\mathrm{b}$ ased $\mathrm{v}$ arnish), $\mathrm{w}$ ater-based $\mathrm{v}$ arnish an d U V varnish [3]. From th e a ngle of e nvironmental $\mathrm{p}$ rotection, $\mathrm{s}$ olvent-based $\mathrm{v}$ arnish will $\mathrm{g}$ radually $\mathrm{b}$ e $\mathrm{r}$ eplaced by water-based varnish and UV varnish. The water-based varnish is easy to get dirty and has slow curing speed a nd o ther s hortcomings. B ut U V varnish has co nsiderable d evelopment b ecause of $\mathrm{i}$ ts fast curing $\mathrm{s}$ peed, without $\mathrm{s}$ olvent $\mathrm{ev}$ aporation, $\mathrm{g}$ reen en vironmental $\mathrm{p}$ rotection an $\mathrm{d} o$ ther advantages. However, traditional UV light curing generally adopts high-voltage mercury lamp and metal halide lamp light source. It would increase high energy consumption, large emissions of thermal and ozone and other issues, which have caused some adverse effects to the UV varnish development. With the development of science and technology, a more environmental friendly curing technology of UV-LED varnish has become a research hotspot in recent years [4]. In the present paper, the basic composition and the problems of UV-LED varnish are reviewed.

a Corresponding author : 1406578878@qq.com 


\section{Overview of UV-LED curing varnish}

UV-LED is t he a bbreviation of $u$ ltraviolet light e mitting di ode.UV-LED 1 ight source uses $t$ he photoelectric conversion principle, electron and the positive charge in the chip collide and bind into light energy in the moving process, making the UV-LED curing more energy saving, environmental protection, and lo ng li ght s ource li fe, lo w r adiation heat [5-6].UV-LED c uring varnish is u sually composed of prepolymer, monomer, photoinitiator and promoter [7].Under the action of the UV-LED light source, monomer and prepolymer make the varnish change from the liquid to the solid product through the cross-linking polymerization.

Prepolymer, also known as oligomer, constitutes the basic skeleton of varnish, is a film forming material of $\mathrm{v}$ arnish $\mathrm{s} y$ stem, a nd $\mathrm{d}$ etermines the $\mathrm{b}$ asic $\mathrm{p}$ roperties of $\mathrm{v}$ arnish. P repolymer co mmonly used i ncludes $u$ nsaturated $p$ olyester, ep oxy acr ylate, $p$ olyurethane acr ylate, $p$ olyester acr ylate, polyether acrylate, and so on [8].

Monomer, a lso known a s a ctive d iluent, c onstitutes b inders of varnish with p repolymer a nd influences the $r$ heological $p$ roperties of $U V \mathrm{v}$ arnish a nd p roperties of the c ured f ilm. I $t \mathrm{n}$ ot o nly regulates $p$ olymerization d egree, vi scosity a nd c uring velocity of va rnish s ystem, b ut a lso a djusts some physical properties such as the chroma, gloss and density. The vi scosity and curing speed of different monomers are affected by the different functionality [9]. Generally the higher the functional degree is, the faster the curing rate is, but the worse the dilution effect is. Commonly used monomer: $\mathrm{M}$ onofunctional monomers, na mely 2 -hydroxyethyl methacrylate ( HEMA), C yclic Trimethylopropane F ormal A crylate ( CTFA), 2 -(2-Ethoxyethoxy) e thyl a crylate(EOEOEA), 2-Phenoxy Ethyl Acrylate (PHEA), N,N -dimethyl-2-Propenamide (DMAA); Bis-functional monomer, namely 1 ,6-Hexanediol d iacrylate ( HDDA) a nd Tripropylene g lycol diacrylate ( TPGDA), Dipropylene glycol diacrylate (DPGDA), Diethyleneglycoldimethacrylate (DEGDMA); Trifunctional and a $\mathrm{p}$ olyfunctional monomer, $\mathrm{n}$ amely $\mathrm{T}$ rimethylolpropanetriacrylate ( TMPTA), E thoxylated ( 5) pentaerythritoltetraacrylate (PPTTA), T rimethylolpropanetrimethacrylate ( TMPTMA), P ropoxylated (6) trimethylolpropanetriacrylate (TMP6POTA).

Photoinitiator, after UV irradiation, absorbs energy to the excited state, forms free radicals or ions, and initiates the unsaturated double bond of monomer and prepolymer to polymerize. The polymer molecules are continuously cross-linked to form a network structure. Until the free radical activity is completely ran out, the chain growth will be over. So the varnish can be completely solidified [10]. As a result, the photoinitiator plays an important role in the varnish curing.

While promoter, an integral part of the varnish system, is accounted for a smaller proportion in the varnish system, $t$ he ef fect o $\mathrm{n}$ the $\mathrm{p}$ erformance of $\mathrm{t}$ he varnish is more i mportant. D ue t o i nherent characteristics of UV-LED curing, some common promoters cannot participate in light curing reaction then stay in the cured film, which will cause some defects such as pinhole, anti-sticking oncured film. So the active promoters participating in the curing reaction should be selected as far as possible when choosing promoters. The leveling agent and wax powder are more used, and mainly regulate the flow of varnish and smoothness.

\section{Problems and countermeasures during the development of UV-LED curing varnish}

\subsection{Problems}

(1) The slow curing speed of UV-LED does not match the printing s peed. At present, the printing speed of offset printing has reached the 18000 sheets / h $(240 \mathrm{~m} / \mathrm{min})$ and that of intaglio printing is $300 \sim 350 \mathrm{~m} / \mathrm{min}$. U V hi gh s peed p rinting s ystems which s peed up to $300 \mathrm{~m} / \mathrm{min}$ has reached the practical level [11]. S ince the c oating a nd c uring p rocess of va rnish is o n-line p rinting, it is very important to increase the curing speed of UV-LED varnish. 
(2) Lack of photoinitiators with absorption characteristic fitting into the narrow emission spectrum of the UV- LED lamp

UV-LED curing process was developed from the UV curing process, the traditional UV curing uses the entire UV wavelength light of 200 450nm. However, most UV-LED curing concentrates in the $395 \sim 405 \mathrm{~nm}$ wavelength, only a few concentrates in the $365 \mathrm{~nm}$ wavelength [12]. Currently on the market, UV-LED curing products mainly have two main types of wavelength, wavelengths of $365 \mathrm{~nm}$ and $395 \mathrm{~nm}$. In the same type of products, $395 \mathrm{~nm}$ wavelength peak intensity is larger than $365 \mathrm{~nm}$. $365 \mathrm{~nm}$ wavelength is short and its energy is high, leading to local overheating, seldom application. So wavelength of mainstream of UV-LED curing application is still $395 \mathrm{~nm}$ on the market. To achieve the better curing speed, absorption spectra of photoinitiators have to fit into the narrow emission spectrum of LED lamp. Photoinitiators applied in UV curing before is no longer applicable for UV-LED curing, in other words, currently the initiator strong absorbing in $395-405 \mathrm{~nm}$ is lacked.

\subsection{Countermeasures}

Most traditional UV curing light source are the high pressure mercury lamp and metal halide lamps, The emission spectra is wide, continuous and greatly different from the emission spectra of LED.Figure 1 is a comparison of spectral irradiance and UV-LED high pressure mercury lamp.

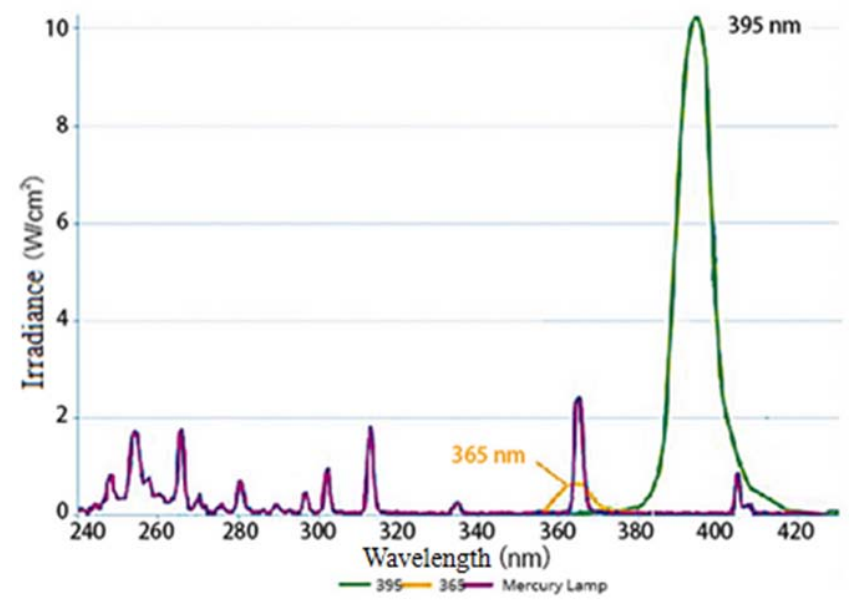

Figure 1.The spectral irradiance of UV-LED and high pressure mercury lamp

Figure 1 is a spectral irradiance comparison of UV-LED and high pressure mercury lamp [11]. The emission spectrum distribution of high-voltage mercury lamp was continuous, and for the LED, based on the 1 imits of the forbidden $b$ and width of the s emiconductor material in e lement, a lthough $t$ he spectral energy is very strong, the wavelength distribution is extremely narrow; Light energy strength emitting from LED specific spectrum is stronger than that from the same spectral of traditional light sources [13]. But from the integral light of the whole emission spectra speaking, LED is not as good as high-voltage mercury lamp; In the same types of products, comparing with $365 \mathrm{~nm}$ light, the power / area (peak irradiance) produced by $395 \mathrm{~nm}$ UV-LED light source is 10 times than the former. So the key a nd difficult $\mathrm{p}$ oint is to select the a ppropriate photoinitiators for d eveloping U V-LED va rnish. Considering $t$ he pos sibility of ba nd ov erlapping, on e or more ph otoinitiators ( or more 1 ikely i s photoinitiator combination) should be studied to provide enough free radicals and initiate the efficient polymerization.

One of the factors that we must be considered when selecting photoinitiators is that the absorption spectrum of the photoinitiators needs to match with the emission spectrum of the light source. Because emission spectrum of high-voltage mercury lamp light source is continuous, conventional UV varnish solidifies in the UV light source of wide band $(250 \mathrm{~nm}$ to $420 \mathrm{~nm})$, more photoinitiators can be selected. Combined photoinitiators have good absorption reaction with different wavelengths of ultraviolet light, 
which ca $\mathrm{n}$ ach ieve the fully cu ring of varnish surface 1 ayer an $\mathrm{d} t$ he $\mathrm{d}$ eep $\mathrm{l}$ ayer. $\mathrm{H}$ owever, $\mathrm{t}$ he photoinitiators $r$ eacting $u$ nder th e $u$ ltraviolet 1 ight e mitting from UV-LED 1 ight source ar e 1 ess. Therefore, it is necessary to select photoinitiators with excellent reaction performance [14].

UV-LED light source emits a specific narrow band ultraviolet light, so photoinitiators of UV-LED varnish no $t$ o nly $r$ equire $t$ he $s$ tronger a bsorption $c$ apacity a nd $r$ eaction e fficiency, $b$ ut a lso $t$ heir absorption band need to match with e mission wavelength, which $\mathrm{c}$ an $\mathrm{r}$ ealize the curing of va rnish layer on the surface and in the interior at the same time [4]. Therefore, when choosing photoinitiators of U V-LED $\mathrm{v}$ arnish, we s hould e nsure $\mathrm{p}$ hotoinitiations $\mathrm{h}$ ave th e $\mathrm{b}$ est a bsorption $\mathrm{c}$ haracteristics a $t$ specific wavelengths of UV-LED light source, meanwhile we also should develop the best ratio of photoinitiators $\mathrm{c}$ omposition $\mathrm{t}$ o a bsorb lim ited $\mathrm{u}$ ltraviolet lig ht a $\mathrm{s}$ much a $\mathrm{s}$ p ossible, to $\mathrm{b}$ alance yellowing and curing of varnish [15].

The main absorption range of the most photoinitiators is listed in Table 1 . We can see that the main absorption range of the most photoinitiators are below peak wavelength range of 365/395nm of LED light. However, UV-LED light source is not a pure monochromatic, most of photoinitiators have wide absorption band. When only considering the maximum value, they are often ignored. Some of the ph otoinitiators i $365 \mathrm{~nm}$ a nd / or $395 \mathrm{n}$ m or a bove region a re $\mathrm{n}$ ot a bsorbed. T able $1 \mathrm{i}$ s the absorption peaksof all kinds of common UV photoinitiators.

Table 1.The absorption peaks of all kinds of common UV photoinitiators

\begin{tabular}{cc}
\hline Type & Absorption Peak/nm \\
\hline 184 & $240-250,320-335$ \\
651 & $330-340$ \\
369 & $325-335$ \\
907 & $320-325$ \\
819 & $360-365,405$ \\
1173 & $265-280$ \\
2959 & $275-285,320-330$ \\
TPO & $350-400$ \\
MBF & 255,335 \\
784 & $380-390,460-480$ \\
TX & $395-430$ \\
ITX & 258,382 \\
389 & 368,492 \\
\hline
\end{tabular}

For U V-LED c uring $\mathrm{v}$ arnish, in o rder to a chieve a b etter e ffect o $\mathrm{f}$ in itiation a nd $\mathrm{c}$ uring, it is necessary to select photoinitiators which absorption peak are more than $365 \mathrm{~nm}$, such as TPO and 819 . Although the absorption peak wavelength of 784 is longer, but the price is so high that it is used less on the market. Moreover, because the amount of residual migration of 184, 907, 1173, MBF, ITX and other photoinitiators is large, their photolysis products are toxic and harmful to the human body and the en vironment, so they are disabled in the cigarette package and food packaging, etc. Toxicology studies s how $t$ hat I TX, as a f at s oluble co mpound, $t$ hrough $t$ he $s$ trong force $b$ etween $t$ he cel 1 phospholipid layers, can affect the movement and hardness of cell membrane, may have an impact on the body's endocrine hormones. In addition, two kinds of photoinitiators BP and 4-MBP have also been shown to have carcinogenic effects, skin contact toxicity and reproductive toxicity. In Europe, trace of ITX was te sted in N estle milk powder in 2005. The reason was that the photoinitiator ITX residues contained in the UV ink in Nestle milk powder packaging materials caused the contamination of milk powder due to migration [16]. Currently Omnipol TX, Omnipol 910, IHT-PI 389 and other environmental products in the UV-LED photoinitiators are available for using. 
In a ddition, most $U$ V-LED curing va rnish a dopts $\mathrm{s}$ ilk $\mathrm{s}$ creen a nd o ffset $\mathrm{p}$ rinting. I $\mathrm{n}$ o rder $\mathrm{t} o$ improve curing speed and curing effect, we can get down to reconstructing the screen printing and offset $\mathrm{p}$ rinting machine. T he ways to $\mathrm{s}$ olve the $\mathrm{p}$ roblem of $\mathrm{p}$ oor $\mathrm{c}$ uring e ffect of the LED $\mathrm{c}$ uring currently include retaining a group of mercury lamp from three group of standard mercury lamp of original o ffset p rinting machine, installing LED l ight s ource $\mathrm{c}$ uring system a nd c ombining the UV curing mercury la mp with $\mathrm{L}$ ED lig ht $\mathrm{c}$ uring. A fter th e im provement of the te chnology of the prepolymer, i nitiator a nd a ctive monomer for varnish, the $t$ raditional $U \mathrm{~V} c \mathrm{c}$ uring $\mathrm{s}$ ystem would b e completely replaced by UV-LED curing.

LED c uring with low e nergy consumption requires hi gh reaction a ctivity c uring va rnish system. Along with the progress of the raw materials, new hyperbranched high reaction oligomer, for example, Sartomer C N 2303, a lkoxylate $\mathrm{m}$ ultifunctional a crylate o ligomer, a nd m ulti-functional gr oups monomers, and new photoinitiators with maximum absorption peaks in $395 \sim 405 \mathrm{~nm}$ will be developed and applied inUV-LED curing system. The curing rate and the curing film performances of UV-LED varnish would be improved.

\section{Conclusions}

The UV-LED curing with characteristics of efficiency, no emissions of VOC, ozone and $\mathrm{Hg}$ as well as low p rocess t emperature will $g$ radually $r$ eplace the $t$ raditional $h$ igh $p$ ressure mercury lamp cu ring. Namely, UV-LED curing varnish will replace traditional UV curing varnish and become development trend of the varnish market in the future. However, in the development process of UV-LED c uring varnish, the lo w e fficiency of $\mathrm{p}$ hotoinitiations a nd $\mathrm{s}$ low $\mathrm{c}$ uring s peed a re the key problems. N ow market urgently need the photoinitiators with maximum absorption in the wavelength of the $395 \sim 405 \mathrm{~nm}$. By improving raw materials properties and optimizing formulation, the aim of increasing the curing speed and enhancing the properties of curing film and promoting the development of print finishing processing technology could be reached.

\section{Acknowledgements}

This work was financially supported by the Special Project of Quality Inspection of Public W elfare Industry Research (201410039).

\section{Reference}

1. Xirong Chen. A discussion on the technology and application of $U V$ varnish $[\mathrm{J}]$. China Packaging, 02: 55-59(2007).

2. Guangzhen $\mathrm{H} \mathrm{u}, \mathrm{X}$ iaoming Song. $\mathrm{T}$ he $\mathrm{d}$ evelopment o verview of water-borne va rnish [ J] . Guangdong Printing, 04: 57-58(2012).

3. Decang Chen. Analysis of water-borne varnish [J]. Print Today,05: 64-66 (2006).

4. Shifan Z hang, Yongsheng Ma, Weiwei Huang. Application of UV-LED technology in number ink [J]. Label Technology, 05:30-31 (2015).

5. Stephen B S iegel. U V C ommercialization of LED C uring [C]. P roceedings of R ad T ech Asia 2005. Shanghai: Rad Tech Asia Organization, 2005: 339-356.

6. Dongliang J i, Application a nd de velopment trend of LED on UV p rinting [J]. Printing F ield. 2010(5):56-58.

7. FayiHao. The study of special effecting of UV-cured coating [D].Xi'an University of Technology, (2003)

8. Xinxin C ao, $\mathrm{T}$ ing $\mathrm{Z}$ hang. T he R evolutionary I nfluence of L ED Light S ource o n P CB Ink [ J]. Information Recording Materials, 04:57-60 (2014).

9. Qing Yi. Research on UV-LED inkjet ink [D]. Nanjing Forestry University,(2014) 
10. Lei Zhao. Study on the formulation and printability of UV curable offset ink [D]. Beijing Institute of Graphic Communication, (2007)

11. Zhigang $\mathrm{Y}$ ang. The p rinciple and c haracteristics of LED c urable in $\mathrm{k}[\mathrm{J}]$. P rinting $\mathrm{W}$ orld, 06: 4-7(2009).

12. Lei Zhang. The development trend of UV-LED c uring t echnology [ J] .Electronic Components and Materials, 06: 99-100(2015).

13. Yiwen Wei. Application of LED-UV in the offset printing [J]. Guangdong Print, (2013)06: 40-42.

14. Rui Wang. The application of UV LED technology in the field of printing [J]. Print Today, 11: 61-62(2013).

15. Zhibiao $\mathrm{Z}$ hang. L ED-UV c uring $\mathrm{t}$ echnology, $\mathrm{t}$ he $\mathrm{s}$ tar o f e nergy s aving a nd e nvironmental protection [J].Printing Technology, 06: 40-41 (2014).

16. Dongxu $\mathrm{S}$ hen, $\mathrm{H}$ ongzhenLian, $\mathrm{T}$ ao $\mathrm{D}$ ing, Congyu $\mathrm{S}$ hen. A Review o $\mathrm{nt}$ he Analysis o $\mathrm{f}$ Photoinitiator Residues[J]. Rock ore testing, 01:104-109(2011). 